Editorial

\title{
Political Agency at the Digital Crossroads?
}

\author{
Anne Kaun ${ }^{1, *}$, Maria Kyriakidou ${ }^{2}$ and Julie Uldam ${ }^{3}$ \\ ${ }^{1}$ Media and Communication Studies, School for Culture and Education, Södertörn University, 14189 Hudding, Sweden; \\ E-Mail: anne.kaun@sh.se \\ ${ }^{2}$ School of Politics, Philosophy, Language and Communication Studies, University of East Anglia, Norwich, NR4 7TJ, UK; \\ E-Mail: m.kyriakidou@uea.ac.uk \\ ${ }^{3}$ Department of Communication and Arts, Roskilde University, 4000 Roskilde, Denmark; E-Mail: uldam@ruc.dk \\ * Corresponding author
}

Submitted: 20 June 2016 | Published: 11 August 2016

\begin{abstract}
This thematic issue presents the outcome of the 2015 ECREA Communication and Democracy Section Conference "Political Agency in the Digital Age" that was held at the Copenhagen Business School in Denmark. It problematizes changes in the configurations of political agency in the context of digital media. The articles represent a shift from an exclusive focus on political elites to the interrelation between institutionalised politics and political processes in other societal spheres in the field of media and politics research. Political agency as the main notion of the thematic issue draws attention at the (media) practices through which social actors reproduce, reorganise and challenge politics. At the same time, the issue poses questions about the structures-economic, political and social-that allow for, define and also limit these practices. The contributions gathered here suggest an understanding of agency as constituted through the use of knowledge and resources, themselves embedded within structural contexts; at the same time, agency is transformative of the structures within which it is embedded by making use of knowledge and resources in creative and often radical ways. In that context the development of digital media marks a rupture or critical juncture that allows and requires a rethinking of conditions of political agency. Accordingly the contributions critically scrutinize the role of digital media moving beyond celebratory accounts of democratizing potential of digital media. The rethinking of the grammar of political agency is at the heart of this thematic issue.
\end{abstract}

\section{Keywords}

digital media; media practices; political agency; political participation

\section{Issue}

This editorial is part of the issue "Political Agency in the Digital Age: Media, Participation and Democracy", edited by Anne Kaun (Södertörn University, Sweden), Maria Kyriakidou (University of East Anglia, UK) and Julie Uldam (Roskilde University, Denmark).

(C) 2016 by the authors; licensee Cogitatio (Lisbon, Portugal). This article is licensed under a Creative Commons Attribution 4.0 International License (CC BY).

Research on media and politics has traditionally tended towards separating the sphere of politics from political processes in other societal spheres, focusing on parliamentarian politics and formal, institutionalised interest group politics (e.g. unions). At the same time, there has been a tendency to focus on elites, whether political, corporate, media or cultural. With the emergence of digital media, the research agenda within the field of media and politics research is shifting towards exploring interrelations between institutionalised poli- tics and political processes in other societal spheres, and moving beyond elites to also include "ordinary" people. The personalization of digital media and the rise of user-generated content have led to an increased interest in personal self-expression of citizens as a political act. While this represents an important development, it also warrants fundamental questions about what counts as politics and who counts as political actor. At the same time euphoric accounts of the potential of digital media for political agency are questioned 
critically both in terms of effectiveness and the wider structures in which they are embedded. The thematic issue gathers articles that provide a varied analysis of political agency in the digital age assuming that political agency emerges at the intersection of socially and technologically embedded media practices and experiences. In that context the development of digital media marks a rupture or critical juncture that allows and requires a rethinking of conditions of political agency. The rethinking of the grammar of political agency is at the heart of this journal.

The notion of 'political agency' draws attention at the (media) practices through which social actors reproduce, reorganise and challenge politics. At the same time, it poses questions about the structures, economic, political and social, that allow for, define and also limit these practices. We understand agency as constituted through the use of knowledge and resources, themselves embedded within structural contexts; at the same time, agency is transformative of the structures within which it is embedded by making use of knowledge and resources in creative and often radical ways. In practical terms political agency refers to acting on political, economic and social structures in order to promote social change or, as Anthony Giddens has defined it, a 'capacity to make a difference' (Giddens, 1984 , p. 14). This focus on political agency, therefore, requires an understanding of empowerment, participation and social change as contextual and as processes that are constantly negotiated. It, therefore, allows us to escape the emerging dichotomy between celebratory and pessimistic narratives about the political participation as enabled by digital media.

In this context, the concept of the 'digital age' invites us to think of digital media, and in particularalthough not exclusively-social media platforms such as Facebook and Twitter, as part of the social, economic, and technological ecologies that allow for and enable the expression of political agency in particular ways (Mercea, lannelli, \& Loader, 2016). This is not to say that these media are the catalyst of new and revolutionary forms of political agency. Beyond the technooptimism expressed in arguments about 'Facebook' or 'Twitter revolutions', we do not see technology and new media as independent actors in themselves but rather as emerging in the context of specific cultural and societal settings while having specific technological properties (Williams, 1974, 1977). Consequently, we consider media practices as both social and material processes. While social aspects of media practices are increasingly at the heart of empirical investigations particularly in the context of political participation (see for example Couldry, 2012; Mattoni \& Treré, 2014), there is still a lack of exploring material aspects of media practices. Besides exploring changes in patterns of political agency in the digital age, the thematic issue hence aims to suggest empirical investigations of mate- rial aspects of media practices.

It is important to consider agency as enabled by and performed through digital media both in its individual and collective expressions. Earlier research on digital media has emphasised their emancipatory potential for individual users and highlighted individual creative autonomy as the basis for political participation and social change. In his overly optimistic account, Henry Jenkins (2006) has used the term 'photoshop democracy' to describe how fan engagement with popular culture, further enabled by new media, can lead to political action and a more democratic participatory culture. In similar lines, John Hartley's concept of 'do-it-yourself citizenship' (1999, 2010) , emphasising television viewers' agency, has been applied on discussions about practices of citizen-making through interactions and creative explorations on online media (Ratto \& Boler, 2014). Such forms of political agency, van Zoonen, Visa and Mihelja (2010) argue are forms of 'unlocated citizenship', namely of citizenship not necessarily linked to established political institutions. Social media platforms can form the space where such citizenship is fostered, in ways that are 'self-actualising' rather than 'dutiful' (Bennett, Wells, \& Rank, 2009).

These approaches are underlined by the assumption that self-expression on online platforms is a political act and can become a tool of resistance. Communicative autonomy afforded on digital media, Castells argues, directly fosters 'social and political autonomy', themselves key factors of social change (Castells, 2009, p. 414). Major characteristic of such forms of action, according to Bennett is the emergence of the individual as an important catalyst of collective action through the mobilisation of her social networks, itself enabled through the use of social media (Bennett, 2012, p. 22). Such networked action is an expression of 'personalised politics', as it is conducted across personal action frames, which embrace diversity and inclusion, lower the barriers of identification with the cause, and validate personal emotion (Bennett, 2012, pp. 22-23). In this context, 'connective action' is substituting 'collective action' at the public space (Bennett \& Segerberg, 2013).

On the other hand, a number of studies have explored political agency in the forms of collectivities organised and mobilised through new media platforms (della Porta, Andretta, Mosca, \& Reiter, 2006; Gerbaudo, 2012; Kavada, 2015; Mercea, 2012; Treré \& Mattoni, 2015; Uldam, 2010). These studies have emphasised how the collective agency of social movements, such as the global justice movement, environmental activism, or anti-austerity protests, has been enabled and reinforced through new media and the practices of collective identification they allow for. In this context, technology plays an important symbolic role in the formation of movement identity. Taking Alberto Melucci (1996) and his analysis of collective identity as a starting point, Gerbaudo and Treré (2015) consider hashtags and viral images 
as well as other forms of online mobilizations as vivid examples of collective identity in the context of digital media. 'Social media, as a language and a terrain of identification', Gerbaudo argues, 'becomes a source of coherence as shared symbols, a centripetal focus of attention, which participants can turn to when looking for other people in the movement' $(2014$, p. 266).

However, the potential of digital media for the formation of collective identification is still being questioned on the basis of their inherently individualized character, particularly given the corporate nature of social media. These platforms operate on the basis of a business model that puts data at the heart of the enterprise. Hence, the generation of ever new data becomes the main interest of commercial platforms shifting the emphasis from the use value of messages posted to their exchange value (Dean, 2008; Kaun, 2016). Techno-optimist approaches to the political potential of social media, Fenton and Barassi argue, largely ignore the actual uses to which social networking is put, as well as the fact that within the contemporary political context 'personalised politics' (Bennett, 2012) are actually an expression of individualistic politics conducive to neoliberalism (Fenton \& Barassi, 2011, p. 191).

Moving beyond debates about personalised vs individualistic politics or collective vs connective action, Anastasia Kavada in her contribution in this issue suggests approaching the collective 'in looser terms, as a process rather than as a finished product' (Kavada, 2016, p. 9). Central in this process is communication, and by extension the media, which constitute sites of conversation, each with different affordances for interaction, but also overlapping and interconnected (see also Kavada, 2015). In this context, Kavada argues, collective political agency should not be merely conceptualised in relation to its effectiveness but also in relation to the 'communication capacities' of social movements, which 'include the control, creation and manipulation of the rules of communication themselves and of the sites where episodes of interaction take place' (Kavada, 2016, p. 10). In conclusion, Kavada argues that digital media have made it necessary to consider communication as central in order to understand current social movements. Extending the idea that movements are always in the making, communication becomes consequently crucial for making sense of the changing nature of political agency.

Communication, and in particular its narrative form, is also the focus of Guobin Yang's contribution in this issue. Similarly to Kavada, Yang emphasises the processual character of social movements and the centrality of communicative practices in their constitution. Adapting Campbell's definition of rhetorical agency as the capacity to speak in a way recognised by others (Campbell, 2005), Yang explores narrative agency in relation to hashtag activism, and in particular the \#BlackLivesMatter movement. Comments and retweets in re- sponse to hashtags can be thought of as personal stories appearing in a temporal order, which, once part of the Twitter platform, assume a narrative form. Narrative agency, therefore, as 'the capacity to create stories on social media by using hashtags in a way that is collective and recognized by the public' (Yang, 2016, p. 14) is a central form of agency in digitally mediated political participation. This combination of personal stories and comments and their public recognition which constructs them as collective narratives once again shows the interconnection between the personal and the collective.

If political agency is approached as a process, and communication practices are central in its formation, it is also important to see how these practices are directed towards political change and negotiate with structures and institutional political actors. This question redirects attention to the social and political contexts 'within which new projects of positive political action (policy promotion, advocacy, implementation) can emerge and be sustained' (Couldry, 2012, p. 114). Digital media can be seen as not only enabling but also amplifying political agency by facilitating networking among individuals, social movements, alternative media, and nongovernmental organisations. Networked campaigns of the kind have the potential of influencing public debate, setting agendas and ultimately contributing to policy changes (Benkler, Roberts, Faris, SolowNiederman, \& Etling, 2015; Wilkin, Dencik, \& Bognár, 2015). Such campaigns, however, note the critics, tell us little about how to 'sustain political agency in time' (Couldry, 2012, p. 116) but rather draw attention to isolated acts of disruption. According to Couldry, possibilities of transformative political action are silently weighted towards short-term disruptive interventions and away from long-term positive projects' (Couldry, 2012, p. 125).

Jonas Kaiser, Markus Rhomberg, Axel Maireder and Stephan Schlögl offer a rather pessimistic perspective on this debate in their contribution in this thematic issue. Focusing on the controversial debate on energy resources in Germany (Energiewende), the authors explored the different actors that used digital communication platforms to make their voices and interests of the issue heard. These actors included public administration, other political actors, private business, special interest groups, the media, scientists and civil society. Analysing hyperlink structures on the debate and among these actors, the authors concluded that there was little communication among different actors, as most of them 'only interact with other closely associated actors from their own social field' (Kaiser, Rhomberg, Maireder, \& Schlögl 2016, p. 27). At the same time, the claims of NGOs, civic movements and scientific institutions have been largely ignored by political actors. Whereas, however, political actors seemed preoccupied with inter-party community building, actors from the civ- 
il society and special interest groups did seem to reach out to other actors. This did not change, however, the overall image of the online discourse on 'Energiewende' as fragmentary rather than integrative.

In juxtaposition to such an exclusive focus on online publics, Kerry McCallum, Lisa Waller and Tanja Dreher in their contribution to this issue show how public discussion facilitated by alternative and digital media can actually influence public debate and policy making, providing voice to the marginalised. The authors examine the intersections among the media practices of policy makers, journalists and Indigenous participatory media in the case of a state-sponsored campaign to formally recognize Indigenous people in the Australian constitution. Adopting a mediatisation perspective and conducting multi-sided analysis, they illustrate the complexity of political agency moving between different sites and media formats. 'A changing media environment', the authors conclude, 'has enabled new players and platforms to execute political agency' and challenge established dynamics, therefore disrupting 'how political elites manage public debate, and the way public opinion is understood and acted upon' (McCallum, Waller, \& Dreher, 2016, p. 31).

As the contributions mentioned above show, focusing on political agency as a process constituted through communicative practices allows us to answer questions of how political action, collective and connective, is enabled through digital platforms used by individual and collective social actors coming together. It also allows us to; consider the interaction among different actors and develop an understanding of how existing symbolic, social and political hierarchies structure such communicative practices. Symbolic practices of communication such as discursive struggles over the power to interpret social reality, challenge established political definitions or be heard in the public space are in that context crucial media practices.

If we approach practices, however, not only as symbolic but also as material, in other words as physical and informational work attached to specific technologies, requires us to ask more specific questions about the socio-economic conditions within which these practises occur as well as how they contribute to broader ideological and material fields of cultural production. Such questions have been addressed by a number of critical accounts. Discussions of the digital divide linked to unequal access to communication infrastructures have highlighted structural disadvantages of being excluded from communication (Norris, 2001; Selwyn, 2003; Warschauer, 2004). In contrast considerations of digital labour highlight inequalities that emerge from unequal power relations in the production process of the digital economy, including the exploitation of precarious workers producing the material devices that make online communication possible in the first place (Fuchs, 2015; Scholz, 2012). At the same time, commercial social media constitute fields for corporate surveillance limiting political agency of activists struggling for social change (Uldam, 2016), as well as individual users' privacy by monitoring their data for the purposes of effective advertising (Turow, 2012). Following these critical discussions of material aspects of digital media, political agency is limited within the structures of capitalism, which is reproduced by patterns of ownership and commodification of the online space.

Within this context, Julia Verkova's contribution in this issue provides critical insights into the development of free software and the practices of digital artists, animators and technicians working in digital media industries. Drawing upon an ethnographic study of the production of two free software tools, namely Blender and Synfig, Velkova illustrates the inherent tensions in the production of free software within the context of digital industries operating within a context of 'flexible capitalism'. A series of interviews with developers and technicians reveal that free software becomes meaningful for creators as an 'individual strategy to remain flexible and competitive' (Velkova, 2016, p. 51) rather than as a way of self-realisation or emancipation from the industry. In this context the role of free software within digital production, far from being part of a critical project, should be understood as 'individual strategies to find material security and extend personal creative and craft autonomy through technological choices' (Velkova, 2016, p. 51). As such creative agency ultimately illustrates the 'new spirit of capitalism' (Boltanski \& Chiapello, 2007).

Another aspect of materiality, hitherto largely ignored and unexplored, is that of non-participation in the digital space. Non-participation can have the form of passive exclusion from digital use of new media due to socioeconomic reasons, as described by the concept of the digital divide. At the same time, however, nonparticipation can be active, in the sense of choosing to abstain from online platforms. The political dimensions of such acts of abstention, similarly to participation, should be thought of as contextual and therefore open to empirical investigation. For Portwood-Stacer (2013), for example, resisting Facebook can be seen as a performance of elitism on the basis of arguments of taste and distinction. On the other hand, Casemajor, Couture, Delfin, Goerzen and Delfanti (2015) have highlighted how non-participation can be seen as an active rejection of the 'dark sides' of participatory media, such as surveillance, and therefore be politically significant. Similarly, Fenton and Barassi's (2011) interviewees at the Cuba Solidarity Campaign in the UK were concerned that the use of social networking sites as tools of political action might have negative effect on their campaign, distorting people's ideas of collective action.

It is non-participation as a form of protest and claiming autonomy that is the focus of the last article of this thematic issue by Linus Andersson (2016). Ex- 
ploring the practices of radical left groups in Sweden, the author applies a model of non-participation that distinguishes between active and passive nonparticipation. Whereas active non-participation is a form of empowerment and political agency, passive non-participation maps on to forms of non-voluntary exclusion such as the digital divide based on location and socio-economic background. The left groups included in the sample actively chose to abstain from corporate social media as an expression of their ideological leaning and values the groups identify with. Consequently, political agency emerges in media practices of non-usage and abstention that point to structural constraints of digital media for political engagement.

The articles gathered in this thematic issue address the question of how political agency is renegotiated in the digital age through exploring concrete expressions of the dialectical relationship between agency and media in different cultural, political and economic contexts. What the contributions show is that in the era of digital media political agency is necessarily emerging in and through digital media even when it is articulated as a rejection of digital media. This shifts the focus from the question if digital media enable political agency towards how political subjectivity is negotiated in digital media ecologies. It also points to the fact that a distinction between individual and collective forms of political engagement is increasingly blurred. While corporate social media focus predominantly on individual usage, their infrastructures are appropriated for collectivising practices. It hence remains important to see media practices in their broader context countering a media-centric, techno-deterministic view.

\section{Acknowledgements}

We would like to thank the publication committee of Södertörn University that generously provided extra funding for the publication of the thematic issue. Furthermore, we extend our thanks to the members of the Communication and Democracy Section of the European Communication Research and Education Association (ECREA) constituting a vivid and engaged community of scholars and activists interested in the discussion of political participation, (digital) media and social change.

\section{Conflict of Interests}

The authors declare no conflict of interests.

\section{References}

Andersson, L. (2016). No digital "castles in the air": Online non-participation and the radical left. Media and Communication, 4(4), 53-62.

Benkler, Y., Roberts, H., Faris, R., Solow-Niederman, A., \& Etling, B. (2015). Social mobilization and the net- worked public sphere: Mapping the SOPA-PIPA debate. Political Communication, 32(4), 594-624.

Bennett, W. L. (2012). The personalization of politics political identity, social media, and changing patterns of participation. The Annals of the American Academy of Political and Social Science, 644(1), 20-39.

Bennett, L., \& Segerberg, A. (2013). The logic of connective action. Digital media and the personalization of contentious politics. New York: Cambridge University Press.

Bennett, L., Wells, C., \& Rank, A. (2009). Young citizens and civic learning: Two paradigms of citizenship in the digital age. Citizenship Studies, 13(2), 105-120.

Boltanski, L., \& Chiapello, E. (2007). The new spirit of capitalism. London: Verso.

Campbell, K. K. (2005). Agency: Promiscuous and protean. Communication and Critical/Cultural Studies, 2(1), 1-19.

Casemajor, N., Couture, S., Delfin, M., Goerzen, M. \& Delfanti, A. (2015). Non-participation in digital media. Toward a framework of mediated political action. Media, Culture \& Society, 37(6), 850-866.

Castells, M. (2009). Communication power. Oxford: Oxford University Press.

Couldry, N. (2012). Media, Society, world. Social theory and digital media practice. Cambridge: Polity.

Dean, J. (2008). Communicative capitalism: Circulation and the foreclosure of politics. In M. Boler (Ed.), Digital media and democracy (pp. 101-121). Cambridge: MIT Press.

della Porta, D., Andretta, M., Mosca, L., \& Reiter, H. (2006). Globalization from below. Transnational activists and protest networks. New London: University of Minnesota Press.

Fenton, N., \& Barassi, V. (2011). Alternative media and social networking sites: the politics of individuation and political participation. The Communication Review, 14(3), 179-196.

Fuchs, C. (2015). Digital labour and Karl Marx. New York and London: Routledge.

Gerbaudo, P. (2012). Tweets and the streets. Social media and contemporary activism. London: Pluto Press.

Gerbaudo, P. (2014). The persistence of collectivity in digital protest. Information, Communication \& Society, 17(2), 264-268.

Gerbaudo, P., \& Treré, E. (2015). In search of the 'we' of social media activism: introduction to the special issue on social media and protest identities. Information, Communication \& Society, 18(8), 865-871. doi:10.1080/1369118X.2015.1043319

Giddens, A. (1984). The constitution of society: Outline of the theory of structuration. Berkeley and Los Angeles: University of California Press.

Hartley, J. (1999). Uses of television. London: Routledge. Hartley, J. (2010). Silly citizenship. Critical Discourse Studies, 7(4), 233-248.

Jenkins, H. (2006). Convergence culture: Where old and 
new media collide. New York: New York University Press.

Kaiser, J., Rhomberg, M., Maireder, A., \& Schlögl, S. (2016). Energiewende's lone warriors: A hyperlink network analysis of the German energy transition discourse. Media and Communication, 4(4), 18-29.

Kaun, A. (2016). Crisis and critique. A history of media participation. London: Zed Books.

Kavada, A. (2015). Creating the collective: Social media, the Occupy Movement and its constitution as a collective actor. Information, Communication \& Society, 18(8), 872-886.

Kavada, A. (2016). Social movements and political agency in the digital age: A communication approach. Media and Communication, 4(4), 8-12.

Mattoni, A., \& Treré, E. (2014). Media Practices, mediation processes, and mediatization in the study of social movements. Communication Theory, 24(3), 252271.

McCallum, K., Waller, L., \& Dreher, T. (2016). Mediatisation, marginalisation and disruption in Australian indigenous affairs. Media and Communication, 4(4), 30-42.

Melucci, A. (1996). Challenging codes: Collective action in the information age. Cambridge: Cambridge University Press.

Mercea, D. (2012). Digital prefigurative participation: The entwinement of online communication and offline participation in protest events. New Media \& Society, 14(1), 153-169.

Mercea, D., lannelli, L., \& Loader, B. D. (2016). Protest communication ecologies. Information, Communication \& Society, 19(3), 279-289. doi:10.1080/136911 $8 X .2015 .1109701$

Norris, P. (2001). Digital divide: Civic engagement, information poverty, and the Internet worldwide. Cambridge: Cambridge University Press.

Portwood-Stacer, L. (2013). Media refusal and conspicuous non-consumption: The performative and political dimensions of Facebook abstention. New Media \& Society, 15 (7), 1041-1057.

Ratto, M., \& Boler, M. (2014). DIY citizenship: Critical making and social media. Cambridge and London: MIT Press.
Scholz, T. (Ed.). (2012). Digital labor: The Internet as playground and factory. London: Routledge.

Selwyn, N. (2003). Apart from technology: Understanding people's non-use of information and communication technologies in everyday life. Technology in Society, 25(1), 99-116. doi:10.1016/S0160-791X(02)000 62-3

Treré, E., \& Mattoni, A. (2015). Media ecologies and protest movements: Main perspectives and key lessons. Information, Communication and Society, 19(2), 290306. doi:10.1080/1369118X.2015.1109699

Turow, J. (2012). The daily you: How the new advertising industry is defining your identity and your worth. New Haven and London: Yale University Press.

Uldam, J. (2010). Fickle commitment. Fostering political engagement in 'the flighty world of online activism' (PhD Thesis), Copenhagen Business School, Copenhagen.

Uldam, J. (2016). Corporate management of visibility and the fantasy of the post-political: Social media and surveillance. New Media \& Society, 18(2), 201219. doi:10.1177/1461444814541526

van Zoonen, L., Visa, F., \& Mihelja, S. (2010). Performing citizenship on YouTube: Activism, satire and online debate around the anti-Islam video Fitna. Critical Discourse Studies, 7(4), 249-262.

Velkova, J. (2016). Free software beyond radical politics: Negotiations of creative and craft autonomy in digital visual media production. Media and Communication, 4(4), 43-52.

Warschauer, M. (2004). Technology and social inclusion: Rethinking the digital divide. Massachusetts: MIT press.

Wilkin, P., Dencik, L., \& Bognár, É. (2015). Digital activism and Hungarian media reform: The case of Milla. European Journal of Communication, 30(6), 682-697.

Williams, R. (1974). Television. Technology and cultural form. New York: Schocken Books.

Williams, R. (1977). Marxism and literature. Oxford: Oxford University Press.

Yang, G. (2016). Narrative agency in hashtag activism: The case of \#BlackLivesMatter. Media and Communication, 4(4), 13-17.

\section{About the Authors}

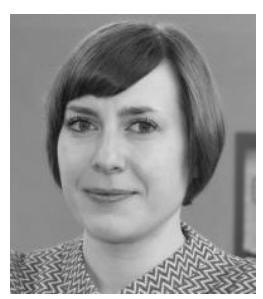

Anne Kaun is Associate Professor in Media and Communication Studies at Södertörn University Kaun's research interest include media activism, temporality of media technologies, and media memories. Her work has appeared in among others New Media and Society, the European Journal of Cultural Studies, Media, Culture and Society. In autumn 2016, her book Crisis and Critique is published by Zedbooks. 


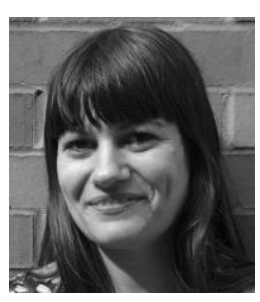

Maria Kyriakidou is a Lecturer of Cultural Politics, Communications and Media at the University of East Anglia. Her research focuses on the intersection between media, politics, and globalisation. Her work has appeared among others in Media, Culture \& Society, the International Journal of Communication, and Communication, Culture \& Critique.

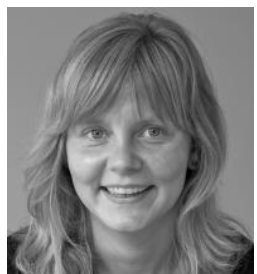

Julie Uldam is Associate Professor at Roskilde University. Her research explores the interrelations between political participation and digital media, especially social movements and social media. Julie's work has been published in peer-reviewed journals, including New Media \& Society, International Journal of Electronic Governance and International Journal of Communication. Her book Civic Engagement \& Social Media was published in 2015. Julie is chair of ECREA's Communication \& Democracy section and chair of the network on Social Innovation and Civic Engagement. 